\title{
Messages from the inside. The dynamic environment that favors intestinal homeostasis
}

\author{
Rajaraman Eri ${ }^{1}$ and Marcello Chieppa ${ }^{2 *}$ \\ 'Mucosal Biology, School of Human Life Sciences, University of Tasmania, Launceston, TAS, Australia \\ ${ }^{2}$ Laboratory of Experimental Immunopathology, IRCCS "De Bellis," Castellana Grotte, Bari, Italy
}

\section{Edited by:}

Nils Yngve Lycke, University of Gothenburg, Sweden

\section{Reviewed by:}

Emma Slack, ETH Zürich, Switzerland Charlotte Slayton KaEtzel, University

of Kentucky, USA

*Correspondence:

Marcello Chieppa, Laboratory of Experimental Immunopathology, IRCCS "De Bellis," Via Turi 27, Castellana Grotte, Bari 70013, Italy e-mail: transmed@irccsdebellis.it
An organism is defined as "an individual living thing capable of responding to stimuli, growing, reproducing, and maintaining homeostasis." Early during evolution multicellular organisms explored the advantages of a symbiotic life. Mammals harbor a complex aggregate of microorganisms (called microbiota) that includes bacteria, fungi, and archaea. Some of these bacteria have already defined beneficial roles for the human host that include the ability to break down nutrients that could not otherwise be digested, preventing the growth of harmful species, as well as the ability to produce vitamins or hormones. It is intuitive that along the evolutionary path several mechanisms favored bacteria that provided advantages to the host which, in return, avoided launching an aggressive immunological response against them. The intestinal immunological response does not ignore the lumenal content, on the contrary, immune surveillance is favored by continuous antigen sampling. Some intestinal epithelial cells (ECs) are crucial during the sampling process, others actively participate in the defense mechanism. In essence the epithelium acts as a traffic light, communicating to the inside world whether conditions are safe or dangerous, and thus influencing immunological response. In this review we will discuss the dynamic factors that act on the intestinal ECs and how they directly or indirectly influence immune cells during states of health and disease.

Keywords: mucosal immunology, intestinal evolution, DCs, intestinal epithelial cells, intestinal inflammation

\section{EVOLUTION OF THE DIGESTIVE SYSTEM}

Evolution is defined as the change in the inherited characteristics of biological populations over successive generations. Evolutionary processes give rise to diversity at every level of biological organization, including species, individual organisms, and molecules such as DNA and proteins (1). Life on Earth originated 3.7 billion years ago. Given that an organism requires the intake of energy to live, several strategies appeared during evolution to obtain efficient food intake and digestion (Figure 1). Organisms that were more efficient in capturing and digesting nutrients could prevail in the battle for the survival of the species. Sponges are recognized as the first multicellular organism to appear on Earth. These multicellular organisms did not have a specialized digestive tract, every single cell obtained and digested food particles by filtering water (2). An important step in the evolution of the digestive system is represented by the digestive sac. Cnidarians are multicellular organisms that represent a crucial step for the evolution of the gastrointestinal tract as they evolved a single opening followed by a cavity that served as a digestive space where extracellular digestion produces products ultimately distributed to the entire body (3). Hydra in particular are elegant multicellular organisms that use their tentacles to introduce food in their gastrovascular cavity (4). Among Hydra another crucial evolutionary step took place in the Hydra viridis. This common organism belonging to the phylum Cnidaria appeared on Earth 580 million years ago. Its characteristic green color derives from cells of the unicellular alga symbiotically living within the cells of the gastrodermis. Maintenance of normal symbionts within host digestive cells at relatively constant numbers is due to their avoidance of host digestion. Symbionts continued to evolve together with the host organism. In humans a complex digestive tract harbors an aggregate of microorganisms (called microbiota) that includes bacteria, fungi, and archaea. Some of these bacteria have already defined beneficial roles for the human host, which include the ability to break down nutrients that could not otherwise be digested, preventing the growth of harmful species, as well as the ability to produce vitamins or hormones. It is intuitive that along the evolutionary path several mechanisms favored the microbiota that was able to provide advantages to the host which, in return, offered a safe home where food routinely arrived. A sick host will stop providing food, thus negatively selecting for microbiota that damaged the host by favoring inflammatory responses or harmful infections. At the same time the host has the challenging duty of allowing controlled microbiota growth and of reacting against possible treats.

\section{INTESTINAL EPITHELIAL CELLS}

The intestinal epithelial is a monolayer of cells responsible for the absorption of nutrients taking place through the epithelial cells' (ECs) luminal side. To maximize this process and obtain the largest surface area the small intestine consist of villi and crypts that tremendously increase the number of ECs. Furthermore the luminal surface of the ECs presents microvilli that further increase the exchange surface area. In humans the overall surface covers approximately $200 \mathrm{~m}^{2}$ (5). This strategy perfectly serves the need 


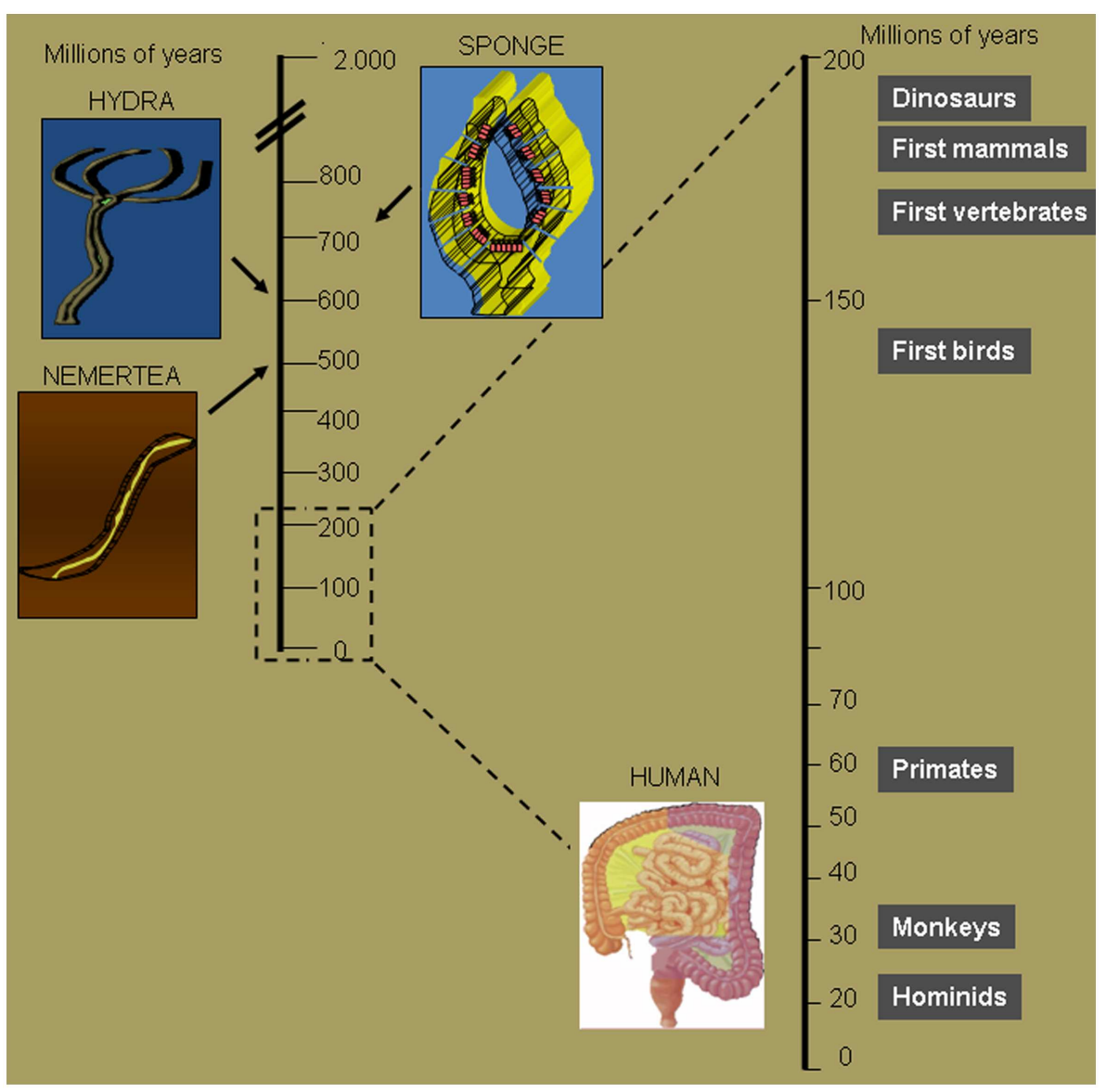

FIGURE 1 | Crucial steps of intestinal tract evolution. Seven hundred millions of years ago sponges were the first multicellular organisms to obtain and digest food particles by filtering water. Six hundred millions of years ago Cnidarians evolved a single opening followed by a cavity that serves as a digestive space. The opening served both as the entrance for food and the exit for waste. It was not until about 100 million years later that, with the Nemertea, waste was eliminated through a second opening, thus maximizing food absorption potential. The first mammals evolved 180 million years ago, but the human intestine first appeared about 160 million years later. to increase nutrient absorption, and at the same time exposes the intestine to the largest possible contact area between the body and the external world via the intestinal lumen. More than 160 species of bacteria populate the intestinal lumen (6). Their density increases along the length of the intestine, peaking in the colon where water is reabsorbed and bacteria are packed and expelled as a major component of feces. Since the first phases of gastrointestinal evolution the ECs monolayer was exposed to challenging conditions given the need for it to be simultaneously a physical, chemical, and electrical barrier between the sterile internal environment and the non-sterile external one. This complex luminal microenvironment is called microbiota and includes bacteria, fungi, nematodes, and viruses. The microbiota has the ability to break down nutrients, produce vitamins or hormones, and prevent the growth of harmful species, all factors that represent an advantage to the host (7). Nevertheless the microbiota is not ignored by the host's defenses, as immune cells and ECs assemble a series of strategies to achieve active vigilance of the luminal content (8-11). All these mechanisms contribute in maintaining a stable state of the internal environment, which is maintained by regulatory processes despite changes that may occur in the external environment, a phenomenon named "homeostasis" in 1929 by W.B. Cannon (12).

\section{EPITHELIAL CELLS SECRETE FACTORS THAT SHAPE THE INTESTINAL LUMEN CONTENT}

The gastrointestinal tract has long been considered to contain the largest number of lymphocytes in the human body, and although recent studies have revised this idea, it has been confirmed that a significant percentage - ranging between 5 and $20 \%$ of all lymphocytes - resides in the gut (13). A dense net of immune cells underlines the ECs monolayer, with distinct aggregates of lymphoid follicles structured as isolated lymphoid follicles (ILFs) in the colon or Peyer's Patches in the small intestine. The intestinal lumen is also the site where the greatest amount of immunoglobulin is secreted, indeed IgA producing B cells are largely "instructed" in the PPs. IgA are extremely important to the correct bacterial distribution along the intestine (14) as demonstrated by an elegant experiment using immunocompetent (scid/+) or immunodeficient (scid/scid) mothers. The neonatal intestinal distribution of Segmented Filamentous Bacteria (SFB) was related to the passively 
acquired maternal secretory IgA (sIgA) in the milk. Milk lacking IgA favored the abnormal SFB colonization of the ileum (15). IgA induction is extremely limited under germ free conditions, but can be rapidly established following intestinal colonization (16). A proliferation-inducing ligand (APRIL) is a key factor for the class switch recombination to IgA, and its production requires TLRs engagement by intestinal ECs (17). sIgA are transported across the ECs into the lumen by the polymeric immunoglobulin receptor (pIgR). As sIgA represent the first line of defense preventing an unneeded pro-inflammatory response as a consequence of the adherence of bacteria to the mucus layer, the induction of pIgR has to be constantly sustained (18-20). Commensal bacteria represent at the same time the stimulus for the coordinated signals that enhance sIgA production and $\mathrm{pIgR}$ expression. Intestinal bacteria promote ECs Thymic Stromal Lymphopoietin (TSLP) production (21). TSLP is an IL-7 related cytokine originally isolated from a mice thymic stromal cell line (22). TSLP signaling is mediated by TSLP binding to the IL-7R $\alpha$ and TSLPR. Experiments that used different approaches, including the TSLPR-deficient mice, were crucial in demonstrating the importance of the TSLP-TSLP axis in the production of APRIL (23), Th2, and Foxp3+ regulatory $\mathrm{T}$ cells $\left(\mathrm{T}_{\text {regs }}\right)$ induction $(8-11,24,25)$ as well as Th1, Th17 inhibition $(26,27)$.

\section{MUCOSAL LAYER MEDIATED PROTECTION}

Epithelial cells are involved in the production of other key players in correct intestinal homeostasis. Among them the mucus layer and the antimicrobial protein (AMP) contribute significantly. The mucus layer is produced by the goblet cells and is fundamental for the protection of the gastrointestinal tract. Its anatomical distribution is consistent with the need to protect the epithelial monolayer and create a disconnection between the body and the luminal content. Indeed the small intestine does not present a well defined mucus layer, as opposed to what happens in the colon and in the stomach (28). The colonic mucus layer is organized in an insoluble inner layer that is relatively sterile, protecting the ECs from bacterial encounter, and a loose outer layer that is well colonized by commensal bacteria (29). MUC2 is the major component of the mucus layer in the small and large intestine and mutations that involve MUC2 are related with chronic intestinal inflammation as a result of uncontrolled ECs exposure to the commensal bacteria $(30,31)$. Another important role of the mucus layer is to concentrate the epithelial AMPs near the epithelial surface. AMPs production is another fundamental mechanism for commensal control and selection. Enterocytes are the major producer of these proteins (32), but immune cells can also efficiently contribute (33). Diverse AMPs are produced in the small or large intestine and even among the same anatomical compartment, while different cells produce different AMPs. Paneth cells located at the base of the intestinal crypts express $\alpha$-defensins (34) and RNase (35), while enterocytes produce C-type lectins in the small intestine (36) and $\beta$-defensins in the colon (35). Together with the antimicrobial effects, these proteins affect the intestinal immune response and in particular contribute to shape the inflammatory response mediated by the intestinal dendritic cells (DCs) underlying the ECs monolayer (37).

\section{INTESTINAL DENDRITIC CELLS}

Dendritic cells are defined as the most potent antigen presenting cells, able to capture, process, and present antigens to initiate the adaptive immune response (38). DCs are distributed all the way through the gut in the lamina propria (LP), gut associated lymphoid tissue (GALT), and in discrete lymphoid aggregates (the latter are generally present in the colon). DCs activate a series of maturational processes in response to microbial antigens exposure that are involved in the innate antimicrobial and inflammatory responses. Furthermore DCs maturation activates T and B cells, initiating the adaptive immune responses (39). Microbial antigens can be detected by the DCs following traumatic events that perturb the natural sterile habitat of the human body. This is not true in tissues like the intestine or the skin where microbes are not only tolerated but even welcome. As aforementioned, the microbiota is an important player for food digestion, vitamin production, and even defense against potential pathogens. The symbiotic coexistence between bacteria and host preexists the development of the immune system, it is therefore not surprising that the immune system evolved mechanisms to avoid potentially dangerous inflammatory responses in these compartments. Intestinal DCs are pivotal for sustaining immune tolerance toward oral antigens. Indeed, DCs promote differentiation, expansion, and maintenance of $\mathrm{T}_{\text {reg }}(40)$ and the induction of IgA producing $\mathrm{B}$ cells against commensal bacteria. The adaptive immune responses initiate in the mesenteric lymph node (MLN) where DCs migrate from the intestine. Worbs et al. demonstrated that genetic defects that alter CCR7 mediated trafficking profoundly affect the induction of tolerance to oral antigens (41).

\section{INTESTINAL DCs SUBTYPES}

Different DCs subtypes coexist in the intestinal LP. Iwasaki et al. first defined intestinal DCs based on the expression of markers such as $\mathrm{CD} 8 \alpha, \mathrm{CD} 11 \mathrm{~b}$, and $\operatorname{CD} 11 \mathrm{c}(42,43)$. More recently the expression of $\alpha \mathrm{E} \beta 7$ (CD103) has been associated with the DCs subset migrating to the MLN and promoting the tolerogenic response. Indeed CD103+ DC are characterized by high levels of retinoic acid (RA) synthesizing enzyme (RALDH), which is crucial for the $\mathrm{T}_{\text {reg }}$ inducing capacity (44). CX3CR1 is another crucial marker that has been used to discriminate intestinal DCs subpopulation. CX3CR1 ${ }^{+}$DCs do not express CD103 and, in marked

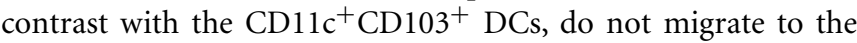
MLN and are poor $\mathrm{T}_{\text {reg }}$ inducers $(45,46)$. In summary $\mathrm{MHCII}^{+}$,

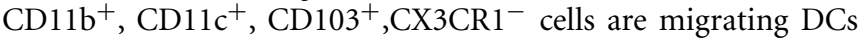
able to promote $\mathrm{T}_{\text {reg }}$ conversion, imprint gut-homing properties and induce $\operatorname{IgA}$ switch, while $\mathrm{MHCII}^{+}, \mathrm{CD}_{11}{ }^{+}, \mathrm{CD}_{11} \mathrm{c}^{+}$, $\mathrm{CD}_{103}{ }^{-}, \mathrm{CX} 3 \mathrm{CR} 1^{+}$are $\mathrm{TNF} \alpha$ producers involved in Th17 induction. Starting from the observation that $\mathrm{CX} 3 \mathrm{CR} 1^{+} \mathrm{DCs}$ are not the MLN migrating DCs, a recent work by McDole et al. (47), focused on $\mathrm{CD} 03^{+}$DCs antigen uptake. This elegant study, which used minimally disruptive in vivo imaging, suggests that small intestine goblet cells deliver soluble luminal antigens to the underlying $\mathrm{CD}_{103}{ }^{+}$DCs. Several studies described the DCs ability to extend processes between ECs, both along the small intestine $(46,48,49)$, in the PPs (50), and the trachea (51). This ability has been related with the need to uptake luminal antigens to be presented in the MLN even in the absence of inflammation. In this regard, Farache 
et al. were able to distinguish the antigen uptake ability of two different DCs populations. Using a CD11c-YFP $\times$ CX3CR $1^{+/ g f p}$ mouse model, they described a population of $\mathrm{CD}_{103}{ }^{+} \mathrm{GFP}^{-}$ YFPint DCs that are able to internalize non-invasive Salmonella by sending dendrites between ECs. At the same time these cells were not as efficient in the uptake of soluble OVA injected into the intestinal lumen, which was mostly internalized by the CX3CR $1^{+}$ macrophage population (46). In addition to the aforementioned uptake mechanisms, an alternative sampling/capturing mechanism has been recently studied. Arques et al. observed $\left(\mathrm{CD} 11 \mathrm{c}^{+}\right.$, $\mathrm{CX}_{3} \mathrm{CR} 1^{+}, \mathrm{MHCII}^{+}, \mathrm{CD}_{11 \mathrm{~b}}^{-}, \mathrm{CD}^{-} \mathrm{a}^{-}$) DCs trans-epithelial migration in the small intestine of Salmonella treated mice (52). The authors suggest that DCs migration in response to TLR5 engagement represents a strategy to prevent or limit the number of pathogens that can penetrate the intestinal epithelium. These hypotheses deserve to be further investigated but represent fascinating mechanisms for the mucosal immune response. At the same time, it is important to better understand the molecular mechanisms that regulate DCs luminal sampling. Different approaches demonstrated that DCs intralumenal sampling is a chemokine related phenomenon (52), but the key factor has still to be identified. It is important to underline that trans-epithelial dendrites have been clearly observed in vitro and in vivo, but considerable differences between studies need to be carefully considered, including those that argue against the relevance of such a mechanism in vivo $(46,47,53,54)$. The in vivo observation of the intestinal lumen requires an invasive procedure that may create acute inflammation and alter the epithelial barrier permeability, eventually inducing apoptosis. Variability between studies may be related to differences in the animal facility condition, starvation periods, or by the procedures required to obtain clean observation areas. Altogether it is clear that intestinal homeostasis is the result of dynamic processes based on vigilant tolerance mediated by antigen presentation in the absence of inflammation. DCs migrating in the MLNs provide the intelligence that decides the outcome of the adaptive response, for this reason so much effort has been devoted to define the intestinal derived factors able to educate the intestinal DCs.

\section{EPITHELIAL DERIVED IMMUNE FACTORS}

The intestinal epithelium evolved to become the largest surface of the body in contact with the external world. The intestinal lumen represents an extremely challenging environment where the need to protect the body from external treats has to coexist with the necessity to permit nutrient absorption. For this reason the largest amount of immune cells resides in close contact with the intestinal ECs. Among them DCs continuously receive signals from the ECs to verify if microbes and ECs are interacting properly. ECs are indeed able to recognize pathogens through a variety of pattern recognition receptors (PRR), including several TLRs expressed on their luminal or basolateral surface (55-57). ECs response to TLRs ligand discriminate TLRs from the luminal or basolateral side. Lumenal TLRs represent constitutive conditions related with the presence of the intestinal microbiota; ECs respond to TLRs engagement by NFkB translocation into the nucleus that leads to the production of chemokines, cytokines (58), and regulate epithelial integrity (59). Basolateral TLRs engagement is more likely related with bacterial invasion or epithelial monolayer discontinuity that results in different types of ECs activation and consequently a pro-inflammatory response (Figure 2). In case of bacterial invasion DCs underlying the ECs monolayer should not be able to respond in an inflammatory way. In fact, DCs conditioned by ECs supernatant lose the ability to produce IL-12 while producing large amounts of IL-10 even following Salmonella exposure $(11,60)$. Efficient inflammatory response needs to be activated by incoming monocytes that differentiate between DCs in a pro-inflammatory environment (61). Resident DCs conditioning is obtained by ECs release of soluble factors - including TSLP (62) and TGF- $\beta$ (31) that appear to synergize in vitro (63). Intestinal DCs also appear to be able to extend processes inside the capillaries of the LP to sample circulating antigens (64). This important observation may shed new light on the connection between inflammatory events that occur in the intestinal compartment and systemic loss of tolerance against self-antigens. More immunomodulating factors may arrive from the intestinal lumen. On this question Agace and Persson recently contributed to the understanding of the role of luminal content in imprinting the unique phenotypic and functional characteristic of intestinal DCs.

\section{LUMENAL PRODUCTS CONDITIONING IMMUNE CELLS}

Food derived factors and the entire microbiota can influence intestinal homeostasis affecting the epithelium or immune cells directly. Vitamins, for example, act directly on the immune system. Vitamin A was recently linked to intestinal immune response as vitamin A metabolite RA is crucial in imprinting gut-homing properties on $\mathrm{T}$ and $\mathrm{B}$ cells (65). Vitamin A is acquired through diet but its active form requires the action of RALDSs to obtain alltrans-RA. Together with the aforementioned gut-homing properties, RA promotes $\mathrm{T}_{\text {reg }}$ and inhibits Th17 differentiation (66). Another RA important feature is the ability to promote B cell class switch imprinting IgA secretion abilities fundamental for correct gut homeostasis and intestinal flora control. Vitamin D, E, and C can act as antioxidants able to modulate immune response (67, 68). Polyphenols are food derived antioxidants also capable of fine-tuning immune response by modulating the maturation of the DCs as shown by the ability of curcumin and resveratrol to suppress inflammatory cytokine secretion through in vitro cultured DCs exposed to LPS (69). Notably, an interesting study by Smith et al. describes the ability of microbial metabolites shortchain fatty acids, to directly enhance colonic $\mathrm{T}_{\text {reg }}$ frequency via GPCR43 expressed by the immune cells (70). Overall, the idea of nutraceuticals (products that have both nutritional and pharmaceutical qualities), a term coined by Stephen DeFelice in 1989 (71), is becoming ever more interesting as we acquire information on how to direct immune response toward tolerance or inflammation, as appropriate. It's not surprising that the major apparatus involved in food derived immunomodulation is the one that is the most exposed to food derived products. An appreciation of the systemic relevance of gut imprinted tolerogenic response will teach us how to modulate inflammation and eventually prevent and cure chronic inflammatory syndromes.

\section{CONCLUSION}

In conclusion, intestinal homeostasis is maintained in a dynamic equilibrium by balancing the contribution of different players. 


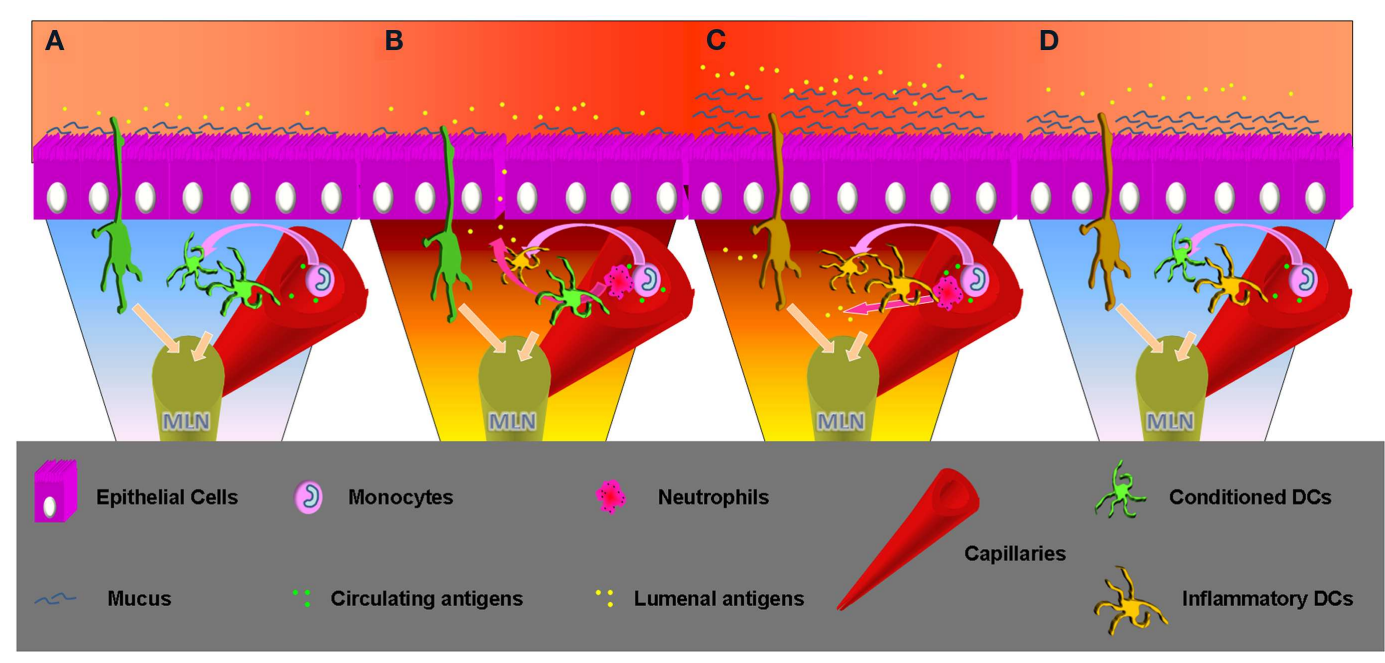

FIGURE 2 |Time progression, from homeostasis to inflammation and inflammation remission. (A) Homeostasis: lumenal and epithelial derived factors imprint an inflammatory impaired phenotype to the intestinal resident DCs. These can sample antigens from the lumen but also from the capillary, but migrating to the MLNs will not produce inflammatory cytokines and will not activate an aggressive adaptive response. Incoming DCs progenitor will enter a favorable environment becoming inflammatory impaired. Sampling circulating antigens these DCs may be crucial to sustain tolerance toward self. (B) Inflammatory insult: epithelial barrier loss or invasive bacteria can change the intestinal milieu, which will lose the ability to condition incoming DCs progenitors. These will possibly encounter lumenal antigens and migrate to the MLN to begin a Th1/Th17 adaptive response. Neutrophils will be recruited as well by the epithelial produced IL-8/KC. Production of this chemokine appears to be mediated by TLR5 engagement that happens in cases of infection. Previously conditioned DCs will not be able to produce an inflammatory response, but migrating to the MLN their effect will be stochastically surmounted by the freshly recruited
DCs if the inflammation is prolonged. (C) Inflammation: incoming inflammatory cells release TNF $\alpha$ that promotes mucus production by goblet cells. A thicker mucus layer better protects from lumenal antigen exposure, important to create the conditions to interrupt the pro-inflammatory cascade. At the same time neutrophils and macrophages clean-up the lamina propria. Incoming DCs progenitors retain the possibility of becoming inflammatory, but the chances decrease in relation with the successful resolution of the infection. Intestinal DCs that sample circulating antigens in pro-inflammatory conditions inside the capillaries may erroneously induce inflammatory responses toward self-antigens. This may enlighten new aspects related with systemic inflammatory responses observed in patients affected by chronic intestinal inflammation. (D) Inflammatory remission: the epithelial barrier is back to normal and epithelial cells are exposed to sustainable amount of antigens. The ECs cytokine cocktail favors DCs polarization to the conventional intestinal phenotype. DCs migrating to the MLN will produce increasing amounts of anti-inflammatory cytokines and correct intestinal homeostasis is finally completed.
Nutritional intake has been the driving force shaping the system and the microbiota, and the body evolved consequently. Many aspects of mucosal immune response have been discovered during the last few decades, but it appears evident that we are still far from a full understanding of the complexity of the system. Oversimplification obtained by in vitro studies or extreme conditions recreated in various mice models are needed to dissect and understand key elements of the system. Nonetheless the complete pattern is still not quite clear, while the rate of intestinal inflammatory disorders

\section{REFERENCES}

1. Mayr E. From molecules to organic diversity. Fed Proc (1964) 23:1231-5.

2. Nielsen C. Six major steps in animal evolution: are we derived sponge larvae? Evol Dev (2008) 10:241-57. doi:10.1111/j.1525-142X.2008. 00231.x

3. Bumann D, Puls G. The ctenophore Mnemiopsis leidyi has a flowthrough system for digestion with three consecutive phases of extracellular digestion. Physiol Zool (1997) 70:1-6.
4. Hohman TC, McNeil PL, Muscatine L. Phagosome-lysosome fusion inhibited by algal symbionts of Hydra viridis. J Cell Biol (1982) 94:56-63. doi:10.1083/jcb.94.1.56

5. Neish AS. The gut microflora and intestinal epithelial cells: a continuing dialogue. Microbes Infect (2002) 4:309-17. doi:10. 1016/S1286-4579(02)01543-5

6. Hooper LV, Midtvedt T, Gordon JI. How host-microbial interactions shape the nutrient environment of the mammalian intestine. Annu Rev Nutr (2002) 22:283-307.

is increasing worldwide, with the consequent urgent need for new and more efficient treatments.

\section{ACKNOWLEDGMENTS}

(MFAG 10684), by the Italian Association for Cancer Research (AIRC), Milan; "GR2009," by the Italian Ministry of Health, Rome; (ARCHES) 5 per mille 2010, Castellana Grotte, Bari. The Italian Translations Company, LLC - Greenbelt, MD, USA http: //italiantranslationscompany.weebly.com/

doi:10.1146/annurev.nutr.22. 011602.092259

7. Tremaroli V, Backhed F. Functional interactions between the gut microbiota and host metabolism. Nature (2012) 489:242-9. doi:10. 1038/nature 11552

8. Goldszmid RS, Trinchieri G. The price of immunity. Nat Immunol (2012) 13:932-8. doi:10.1038/ni. 2422

9. Rescigno M, Chieppa M. Gut-level decisions in peace and war. Nat Med (2005) 11:254-5. doi:10.1038/ nm0305-254
10. Rimoldi M, Chieppa M, Salucci V, Avogadri F, Sonzogni A, Sampietro GM, et al. Intestinal immune homeostasis is regulated by the crosstalk between epithelial cells and dendritic cells. Nat Immunol (2005) 6:507-14. doi:10.1038/nil192

11. Rimoldi M, Chieppa M, Vulcano M, Allavena P, Rescigno M. Intestinal epithelial cells control dendritic cell function. Ann N Y Acad Sci (2004) 1029:66-74. doi:10.1196/annals. 1309.009 
12. Cannon WB. Organization for physiological homeostasis. Physiol $\operatorname{Rev}$ (1929) 9(3):399-431.

13. Ganusov VV, De Boer RJ. Do most lymphocytes in humans really reside in the gut? Trends Immunol (2007) 28:514-8. doi:10.1016/j.it.2007.08. 009

14. Suzuki K, Meek B, Doi Y, Muramatsu M, Chiba T, Honjo T, et al. Aberrant expansion of segmented filamentous bacteria in IgAdeficient gut. Proc Natl Acad Sci U S A (2004) 101:1981-6. doi:10.1073/ pnas.0307317101

15. Jiang HQ, Bos NA, Cebra JJ. Timing, localization, and persistence of colonization by segmented filamentous bacteria in the neonatal mouse gut depend on immune status of mothers and pups. Infect Immun (2001) 69:3611-7. doi:10.1128/IAI. 69.6.3611-3617.2001

16. Hapfelmeier S, Lawson MA, Slack E, Kirundi JK, Stoel M, Heikenwalder $\mathrm{M}$, et al. Reversible microbial colonization of germ-free mice reveals the dynamics of IgA immune responses. Science (2010) 328:1705-9. doi:10.1126/ science. 1188454

17. Shang L, Fukata M, Thirunarayanan N, Martin AP, Arnaboldi P, Maussang $\mathrm{D}$, et al. Toll-like receptor signaling in small intestinal epithelium promotes B-cell recruitment and $\operatorname{IgA}$ production in lamina propria. Gastroenterology (2008) 135:529-38. doi:10.1053/j. gastro.2008.04.020

18. Macpherson AJ, McCoy KD, Johansen FE, Brandtzaeg P. The immune geography of IgA induction and function. Mucosal Immunol (2008) 1:11-22. doi:10.1038/mi.2007.6

19. Phalipon A, Corthesy B. Novel functions of the polymeric Ig receptor: well beyond transport of immunoglobulins. Trends Immunol (2003) 24:55-8. doi:10.1016/S14714906(02)00031-5

20. Bruno ME, Frantz AL, Rogier EW, Johansen FE, Kaetzel CS. Regulation of the polymeric immunoglobulin receptor by the classical and alternative NF-kappaB pathways in intestinal epithelial cells. Mucosal Immunol (2011) 4:468-78. doi:10. 1038/mi.2011.8

21. Mosconi I, Geuking MB, Zaiss MM, Massacand JC, Aschwanden $\mathrm{C}$, Kwong Chung $\mathrm{CK}$, et al. Intestinal bacteria induce TSLP to promote mutualistic T-cell responses. Mucosal Immunol (2013). doi:10. 1038/mi.2013.12. [Epub ahead of print].
22. Friend SL, Hosier S, Nelson A, Foxworthe D, Williams DE, Farr A. A thymic stromal cell line supports in vitro development of surface IgM+ B cells and produces a novel growth factor affecting B and T lineage cells. Exp Hematol (1994) 22:321-8.

23. He B, Xu W, Santini PA, Polydorides $\mathrm{AD}$, Chiu A, Estrella J, et al. Intestinal bacteria trigger $\mathrm{T}$ cell-independent immunoglobulin $\mathrm{A}(2)$ class switching by inducing epithelial-cell secretion of the cytokine APRIL. Immunity (2007) 26:812-26. doi:10.1016/j.immuni. 2007.04.014

24. Ito T, Wang YH, Duramad O, Hori T, Delespesse GJ, Watanabe $\mathrm{N}$, et al. TSLP-activated dendritic cells induce an inflammatory $\mathrm{T}$ helper type 2 cell response through OX40 ligand. J Exp Med (2005) 202:1213-23. doi:10.1084/ jem.20051135

25. Hanabuchi S, Ito T, Park WR, Watanabe N, Shaw JL, Roman E, et al. Thymic stromal lymphopoietinactivated plasmacytoid dendritic cells induce the generation of FOXP3+ regulatory $\mathrm{T}$ cells in human thymus. $J$ Immunol (2010) 184:2999-3007. doi:10.4049/jimmunol.0804106

26. Spadoni I, Iliev ID, Rossi G, Rescigno M. Dendritic cells produce TSLP that limits the differentiation of Th17 cells, fosters Treg development, and protects against colitis. Mucosal Immunol (2012) 5:184-93. doi:10.1038/mi.2011.64

27. Taylor BC, Zaph C, Troy AE, Du Y, Guild KJ, Comeau MR, et al. TSLP regulates intestinal immunity and inflammation in mouse models of helminth infection and colitis. J Exp Med (2009) 206:655-67. doi:10.1084/jem.20081499

28. Johansson ME, Larsson JM, Hansson GC. The two mucus layers of colon are organized by the MUC2 mucin, whereas the outer layer is a legislator of host-microbial interactions. Proc Natl Acad Sci U S A (2011) 108(Suppl 1):4659-65. doi: 10.1073/pnas. 1006451107

29. Hansson GC, Johansson ME. The inner of the two Muc2 mucindependent mucus layers in colon is devoid of bacteria. Gut Microbes (2010) 1:51-4. doi:10.4161/gmic.1. 1.10470

30. Burger-van Paassen N, van der Sluis M, Bouma J, Korteland-van Male AM, Lu P, Van Seuningen I, et al. Colitis development during the suckling-weaning transition in mucin Muc2-deficient mice. Am
J Physiol Gastrointest Liver Physiol (2011) 301:G667-78. doi:10.1152/ ajpgi.00199.2010

31. Eri RD, Adams RJ, Tran TV, Tong $H$, Das I, Roche DK, et al. An intestinal epithelial defect conferring ER stress results in inflammation involving both innate and adaptive immunity. Mucosal Immunol (2011) 4:354-64. doi:10.1038/mi.2010.74

32. Langhorst J, Junge A, Rueffer A, Wehkamp J, Foell D, Michalsen A, et al. Elevated human beta-defensin-2 levels indicate an activation of the innate immune system in patients with irritable bowel syndrome. Am J Gastroenterol (2009) 104:404-10. doi:10.1038/ajg.2008.86

33. Hooper LV, Macpherson AJ. Immune adaptations that maintain homeostasis with the intestinal microbiota. Nat Rev Immunol (2010) 10:159-69. doi:10.1038/nri2710

34. Gallo RL, Hooper LV. Epithelial antimicrobial defence of the skin and intestine. Nat Rev Immunol (2012) 12:503-16. doi:10.1038/nri3228

35. Hooper LV, Stappenbeck TS, Hong CV, Gordon JI. Angiogenins: a new class of microbicidal proteins involved in innate immunity. Nat Immunol (2003) 4:269-73. doi:10. 1038/ni888

36. Vaishnava S, Behrendt CL, Ismail AS, Eckmann L, Hooper LV. Paneth cells directly sense gut commensals and maintain homeostasis at the intestinal host-microbial interface. Proc Natl Acad Sci US A (2008) 105:20858-63. doi:10.1073/ pnas.0808723105

37. Presicce P, Giannelli S, Taddeo A, Villa ML, Della BS. Human defensins activate monocytederived dendritic cells, promote the production of proinflammatory cytokines, and up-regulate the surface expression of CD91. J Leukoc Biol (2009) 86:941-8. doi:10.1189/jlb.0708412

38. Steinman RM, Witmer MD. Lymphoid dendritic cells are potent stimulators of the primary mixed leukocyte reaction in mice. Proc Natl Acad Sci U S A (1978) 75:5132-6. doi:10.1073/pnas.75.10.5132

39. Reis e Sousa C. Activation of dendritic cells: translating innate into adaptive immunity. Curr Opin Immunol (2004) 16:21-5. doi:10. 1016/j.coi.2003.11.007

40. Sun CM, Hall JA, Blank RB, Bouladoux N, Oukka M, Mora JR, et al. Small intestine lamina propria dendritic cells promote de novo generation of Foxp3 $\mathrm{T}$ reg cells via retinoic acid. J Exp Med (2007) 204:1775-85. doi:10.1084/ jem.20070602

41. Worbs T, Bode U, Yan S, Hoffmann MW, Hintzen G, Bernhardt G, et al. Oral tolerance originates in the intestinal immune system and relies on antigen carriage by dendritic cells. J Exp Med (2006) 203:519-27. doi:10.1084/jem.20052016

42. Iwasaki A, Kelsall BL. Localization of distinct Peyer's patch dendritic cell subsets and their recruitment by chemokines macrophage inflammatory protein (MIP)-3alpha, MIP3beta, and secondary lymphoid organ chemokine. J Exp Med (2000) 191:1381-94. doi:10.1084/jem.191. 8.1381

43. Iwasaki A, Kelsall BL. Freshly isolated Peyer's patch, but not spleen, dendritic cells produce interleukin 10 and induce the differentiation of $\mathrm{T}$ helper type 2 cells. J Exp Med (1999) 190:229-39. doi:10. 1084/jem.190.2.229

44. Coombes JL, Siddiqui KR, Arancibia-Cárcamo CV, Hall J, Sun CM, Belkaid Y, et al. A functionally specialized population of mucosal CD103+ DCs induces Foxp3+ regulatory $\mathrm{T}$ cells via a TGF-beta and retinoic acid-dependent mechanism. J Exp Med (2007) 204:1757-64. doi:10.1084/jem.20070590

45. Rivollier A, He J, Kole A, Valatas V, Kelsall BL. Inflammation switches the differentiation program of Ly6Chi monocytes from antiinflammatory macrophages to inflammatory dendritic cells in the colon. J Exp Med (2012) 209:139-55. doi:10. 1084/jem.20101387

46. Farache J, Koren I, Milo I, Gurevich I, Kim KW, Zigmond E, et al. Luminal bacteria recruit CD103+ dendritic cells into the intestinal epithelium to sample bacterial antigens for presentation. Immunity (2013) 38:581-95. doi:10.1016/ j.immuni.2013.01.009

47. McDole JR, Wheeler LW, McDonald KG, Wang B, Konjufca V, Knoop $\mathrm{KA}$, et al. Goblet cells deliver luminal antigen to CD103+ dendritic cells in the small intestine. Nature (2012) 483:345-9. doi:10. 1038/nature10863

48. Niess JH, Brand S, Gu X, Landsman L, Jung S, McCormick BA, et al. CX3CR1-mediated dendritic cell access to the intestinal lumen and bacterial clearance. Science (2005) 307:254-8. doi:10.1126/science.1102901

49. Rescigno M, Urbano M, Valzasina B, Francolini M, Rotta G, Bonasio 
$\mathrm{R}$, et al. Dendritic cells express tight junction proteins and penetrate gut epithelial monolayers to sample bacteria. Nat Immunol (2001) 2:361-7. doi:10.1038/86373

50. Lelouard H, Fallet M, de Bovis B, Meresse S, Gorvel JP. Peyer's patch dendritic cells sample antigens by extending dendrites through $\mathrm{M}$ cellspecific transcellular pores. Gastroenterology (2012) 142:592-601. doi:10.1053/j.gastro.2011.11.039

51. Hammad H, Chieppa M, Perros F, Willart MA, Germain RN, Lambrecht $\mathrm{BN}$. House dust mite allergen induces asthma via Toll-like receptor 4 triggering of airway structural cells. Nat Med (2009) 15:410-6. doi: 10.1038/nm.1946

52. Arques JL, Hautefort I, Ivory K, Bertelli E, Regoli M, Clare S, et al. Salmonella induces flagellinand MyD88-dependent migration of bacteria-capturing dendritic cells into the gut lumen. Gastroenterology (2009) 137(579-87):587. doi: 10.1053/j.gastro.2009.04.010

53. Iwasaki A. Mucosal dendritic cells. Annu Rev Immunol (2007) 25:381-418. doi:10.1146/annurev. immunol.25.022106.141634

54. Vallon-Eberhard A, Landsman L, Yogev N, Verrier B, Jung S. Transepithelial pathogen uptake into the small intestinal lamina propria. $J$ Immunol (2006) 176:2465-9.

55. Rescigno M, Lopatin U, Chieppa M. Interactions among dendritic cells, macrophages, and epithelial cells in the gut: implications for immune tolerance. Curr Opin Immunol (2008) 20:669-75. doi:10.1016/j.coi. 2008.09.007

56. Fukata M, Hernandez Y, Conduah D, Cohen J, Chen A, Breglio $\mathrm{K}$, et al. Innate immune signaling by Toll-like receptor-4
(TLR4) shapes the inflammatory microenvironment in colitisassociated tumors. Inflamm Bowel Dis (2009) 15:997-1006. doi:10.1002/ibd.20880

57. Cario E, Gerken G, Podolsky DK. Toll-like receptor 2 enhances ZO-1-associated intestinal epithelial barrier integrity via protein kinase C. Gastroenterology (2004) 127:224-38. doi:10.1053/j. gastro.2004.04.015

58. Rimoldi M, Chieppa M, Larghi $\mathrm{P}$, Vulcano M, Allavena P, Rescigno M. Monocyte-derived dendritic cells activated by bacteria or by bacteria-stimulated epithelial cells are functionally different. Blood (2005) 106:2818-26. doi:10.1182/blood-2004-11-4321

59. Nenci A, Becker C, Wullaert A, Gareus R, van Loo G, Danese S, et al. Epithelial NEMO links innate immunity to chronic intestinal inflammation. Nature (2007) 446:557-61. doi:10.1038/nature05698

60. Bueno SM, Riquelme S, Riedel CA, Kalergis AM. Mechanisms used by virulent Salmonella to impair dendritic cell function and evade adaptive immunity. Immunology (2012) 137:28-36. doi:10.1111/j. 1365-2567.2012.03614.x

61. Randolph GJ, Inaba K, Robbiani DF, Steinman RM, Muller WA. Differentiation of phagocytic monocytes into lymph node dendritic cells in vivo. Immunity (1999) 11:753-61. doi:10.1016/ S1074-7613(00)80149-1

62. Kashyap M, Rochman Y, Spolski R, Samsel L, Leonard WJ. Thymic stromal lymphopoietin is produced by dendritic cells. J Immunol (2011) 187:1207-11. doi:10.4049/ jimmunol.1100355
63. Zeuthen LH, Fink LN, Frokiaer $H$. Epithelial cells prime the immune response to an array of gut-derived commensals towards a tolerogenic phenotype through distinct actions of thymic stromal lymphopoietin and transforming growth factor-beta. Immunology (2008) 123:197-208.

64. Chang SY, Song JH, Guleng B, Cotoner CA, Arihiro S, Zhao Y, et al. Circulatory antigen processing by mucosal dendritic cells controls CD8(+) $\mathrm{T}$ cell activation. Immunity (2013) 38:153-65. doi:10.1016/ j.immuni.2012.09.018

65. Mora JR, Iwata M, Eksteen B, Song SY, Junt T, Senman B, et al. Generation of gut-homing IgA-secreting $B$ cells by intestinal dendritic cells. Science (2006) 314:1157-60. doi:10. 1126/science.1132742

66. Bai A, Lu N, Guo Y, Liu Z, Chen J, Peng Z. All-trans retinoic acid down-regulates inflammatory responses by shifting the Treg/Th17 profile in human ulcerative and murine colitis. J Leukoc Biol (2009) 86:959-69. doi:10.1189/jlb. 0109006

67. Mora JR, Iwata M, von Andrian UH. Vitamin effects on the immune system: vitamins $\mathrm{A}$ and $\mathrm{D}$ take centre stage. Nat Rev Immunol (2008) 8:685-98. doi:10.1038/nri2378

68. Rezaie A, Parker RD, Abdollahi M. Oxidative stress and pathogenesis of inflammatory bowel disease: an epiphenomenon or the cause? Dig Dis Sci (2007) 52:2015-21. doi:10. 1007/s10620-006-9622-2

69. Vilekar P, Awasthi S, Natarajan A, Anant S, Awasthi V. EF24 suppresses maturation and inflammatory response in dendritic cells. Int Immunol (2012) 24:455-64. doi:10. 1093/intimm/dxr121
70. Smith PM, Howitt MR, Panikov N, Michaud M, Gallini CA, Bohlooly-Y M, et al. The microbial metabolites, short-chain fatty acids, regulate colonic Treg cell homeostasis. Science (2013) 341:569-73. doi:10.1126/science. 1241165

71. Brower V. A nutraceutical a day may keep the doctor away. Consumers are turning increasingly to food supplements to improve well-being when pharmaceuticals fail. EMBO Rep (2005) 6(8):708-11. doi:10. 1038/sj.embor.7400498

Conflict of Interest Statement: The authors declare that the research was conducted in the absence of any commercial or financial relationships that could be construed as a potential conflict of interest.

Received: 26 April 2013; accepted: 23 September 2013; published online: 09 October 2013.

Citation: Eri $R$ and Chieppa $M$ (2013) Messages from the inside. The dynamic environment that favors intestinal homeostasis. Front. Immunol. 4:323. doi: 10.3389/fimmu.2013.00323

This article was submitted to Mucosal Immunity, a section of the journal Frontiers in Immunology.

Copyright (c) 2013 Eri and Chieppa. This is an open-access article distributed under the terms of the Creative Commons Attribution License (CC BY). The use, distribution or reproduction in other forums is permitted, provided the original author(s) or licensor are credited and that the original publication in this journal is cited, in accordance with accepted academic practice. No use, distribution or reproduction is permitted which does not comply with these terms. 